\title{
Behaviour of Tall Structure with Eccentric Loading
}

\author{
Moulshree Tripathi ${ }^{1}$, Mary Wiilaims $\mathrm{P}^{2}$ and Dr R. K. Tripathi ${ }^{3}$
}

\begin{abstract}
Urban planning gives emphasis to vertical expansion. This is achieved by planning and design of high rise structures. This paper discusses behaviour of eccentrically loaded tall building structures with different eccentricities. The study has been conducted using linear static, linear dynamic and nonlinear static analysis with the help of a finite element based software. The parameters considered are Base shear, Storey drift, Torsion and hinge formation in the structure. Various structural arrangements have been proposed based on this study.
\end{abstract}

Keywords - Tall buildings, Asymmetry loadings, linear analysis and non linear analysis.

\section{INTRODUCTION}

Most of the urban settlements are planned and designed on the concept of vertical expansion to save the precious land for other sustainable developments. Vertical expansion is possible only with High rise structures. When these high rise structures have irregular distribution of mass, then their design becomes even more complicated. Due to this asymmetry, torsion is induced in the structure as inertia force acts through the centre of mass while the resistive force acts through the centre of rigidity. This torsional behaviour of asymmetrically loaded structure is one of the most frequent causes of structural damage and failure during strong ground motions.

In this study linear static, linear dynamic and nonlinear static behaviour has been studied with the help of finite element based software. The parameters considered are Base shear, Storey drift, Torsion and hinge formation in the structure. Various structural arrangements have been recommended based on this study.

\section{LITERATURE REVIEW}

Various researchers have worked to study the behaviour of tall structures. Some of notable contributions are mentioned here.

Lee (2004) studied the seismic response characteristics of high-rise Reinforced Concrete wall structures having different

${ }^{1} \mathrm{P}$ h D Research Scholar, Civil Engineering, Indian Institute of Technology Delhi, India

${ }^{2} \mathrm{M}$ Tech Scholar, Civil Engineering, National Institute of Technology Raipur, India

${ }^{3}$ Professor, Civil Engineering, National Institute of Technology Raipur, India irregularities in lower stories and concluded that the existence of shear wall reduces shear deformation at lower frame.

The optimum configuration of a multi-story structure by changing shear wall location was studied and found that column, beam forces are found to increase on grids opposite to the changing position of shear wall away from the centroid of the structure Ashraf et al (2008).

Agrawal et.al (2012) studied effect of change in Shear wall location on storey drift of multi storey structure subjected to lateral loads and stated that placing Shear wall away from centre of gravity resulted in increase in most of the member forces.

The behaviour of G+ 5 storey symmetric structure with various positions and shapes of shear wall was studied by Rahangdale et al., (2013) and found that a box type shear wall at centre is safer than other type of walls placed at different locations.

Chittiprolu et al., (2014) studied on an irregular high rise structure with shear wall and without shear wall to understand the behaviour under lateral loads. They inferred that shear walls are more efficient to resist lateral loads in an irregular structure.

Karnale et al., (2015) stated that the use of shear wall in high rise structure is more effective than use in low rise structure.

\section{ANALYSIS}

A geometrically symmetrical tall building structure has been considered for this study with asymmetric loading. Linear static, linear dynamic and nonlinear static behaviour has been studied with the help of finite element based software. The parameters considered are Base shear, Storey drift, Torsion and hinge formation in the structure.

\section{A. Description of Building Structure}

To study the behaviour of RCC frame structures with asymmetric distribution of mass in plan, a $24 \mathrm{~m} \times 24 \mathrm{~m}$ grid, G+14 storey RCC bare frame has been used.

A total of 109 models, have been analysed each of which as described in Figure 3. 
- No of bays along X axis : 6

- No of bays along Y axis : 6

- Spacing in both directions : $4 \mathrm{~m}$

- No of stories : : G+14

- Storey height $: 3.5 \mathrm{~m}$

- Size of column $\quad: 0.4 \times 0.4 \mathrm{~m}$

- Size of beams $\quad: 0.3 \times 0.4 \mathrm{~m}$

- Slab : $0.12 \mathrm{~m}$ thick

- Shear wall : $\quad 0.2 \mathrm{~m}$ thick

\begin{tabular}{|c|c|c|c|c|c|c|}
\hline$\nabla$ & 1 & 2 & 3 & 4 & 5 & 6 \\
\hline 寸 & 7 & 8 & 9 & 10 & 11 & 12 \\
\hline 寸 & 13 & 14 & 15 & 16 & 17 & 18 \\
\hline$\nabla$ & 19 & 20 & 21 & 22 & 23 & 24 \\
\hline$\nabla$ & 25 & 26 & 27 & 28 & 29 & 30 \\
\hline$\nabla$ & 31 & 32 & 33 & 34 & 35 & 36 \\
\hline
\end{tabular}

Fig. 1. Plan view of the bare frame

hinges are assigned to columns and moment M3 hinges are assigned to beams. Various positions of shear wall as shown below have been considered. Three sets of models, one with eccentric mass of magnituc twice the mass on remaining portion, one with 4 times mass and one with 6 times mass magnitude have been analysed. For pushover analysis, coupled PMM interaction plastic

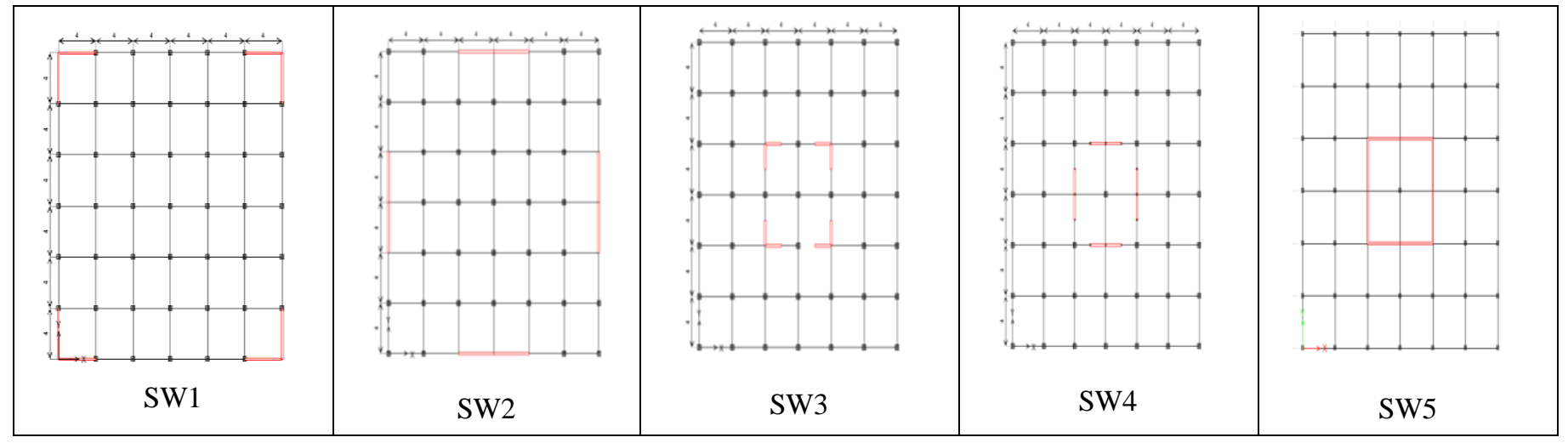

Fig. 1 Mapping nonlinear data to a higher dimensional feature space

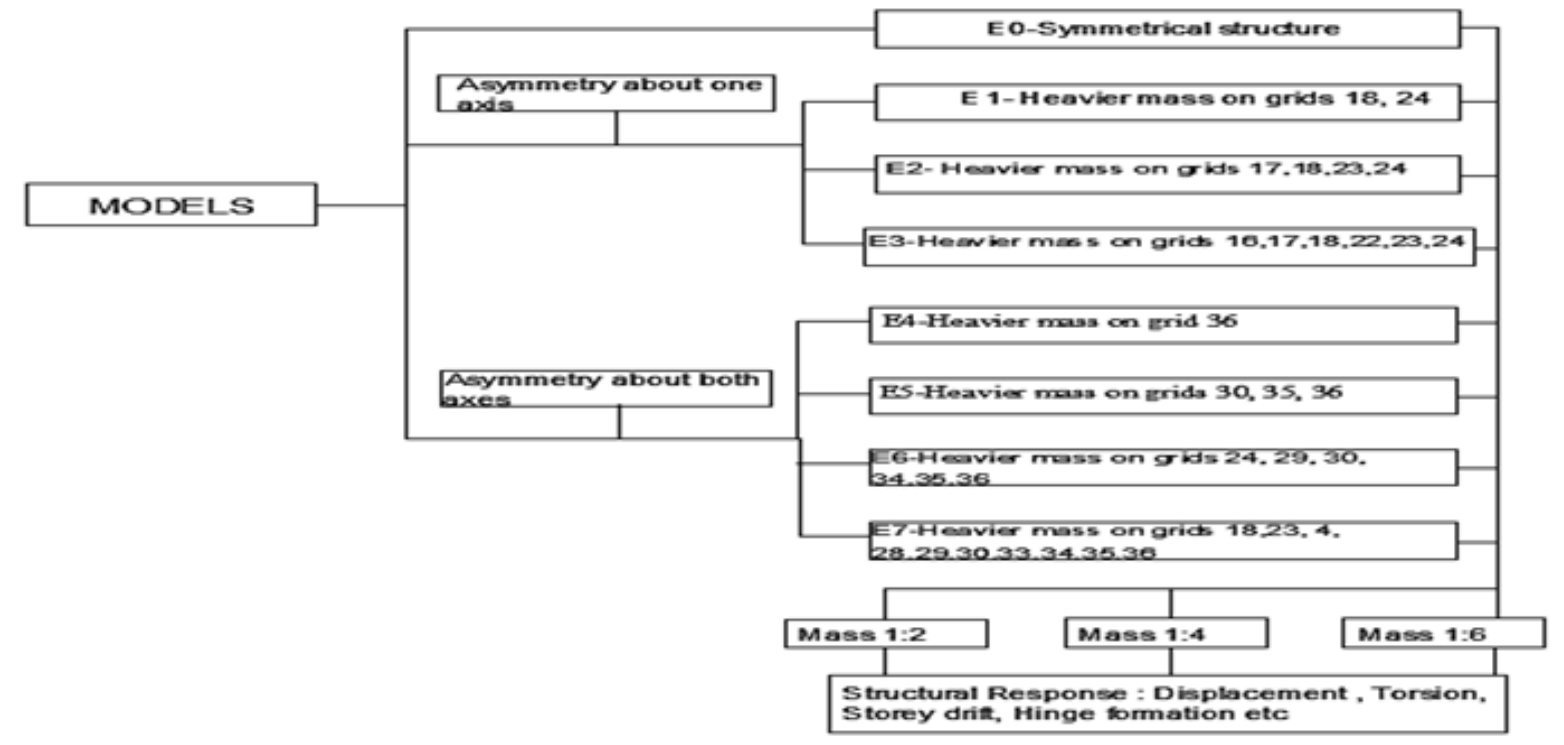

Fig. 3. Description of various load arrangements for the study 


\section{Design Data}

Following design parameters have been considered for the study

Live load $\quad: 3 \mathrm{kN} / \mathrm{m} 2$ on typical floor, Floor finish $: 1 \mathrm{kN} / \mathrm{m} 2$ on typical floor, Earthquake load : As per IS 1893:2002(Part 1) for Type II, Seismic zone : II, Wind load : As per IS 875:1987(Part 3), Class C, Terrain category 3 .

\section{RESULTS AND DISCUSSIONS}

Linear static, linear dynamic and nonlinear static analysis has been performed to investigate the behaviour of the building frame. Various load combinations as per IS 1893:2002 are also used for this purpose. Pushover analysis procedure is followed as per the prescriptions in ATC-40. The hinge properties are applied by default method as per codal provisions in FEMA 356.

\section{A. Eccentricity}

For asymmetric structures the centre of mass and rigidity does not coincide. The eccentricity is defined as the difference between the centre of mass $(\mathrm{CM})$ and the centre of rigidity (CR). The eccentricity due to mass asymmetry in the models are as shown in Figure 4.

As the extent of heavier mass increases, the eccentricity due to mass asymmetry also increases and is observed to be more prominent when the magnitude of mass increases. For the models with shear walls at different locations have almost same eccentricity as the shear wall has been provided symmetrically.

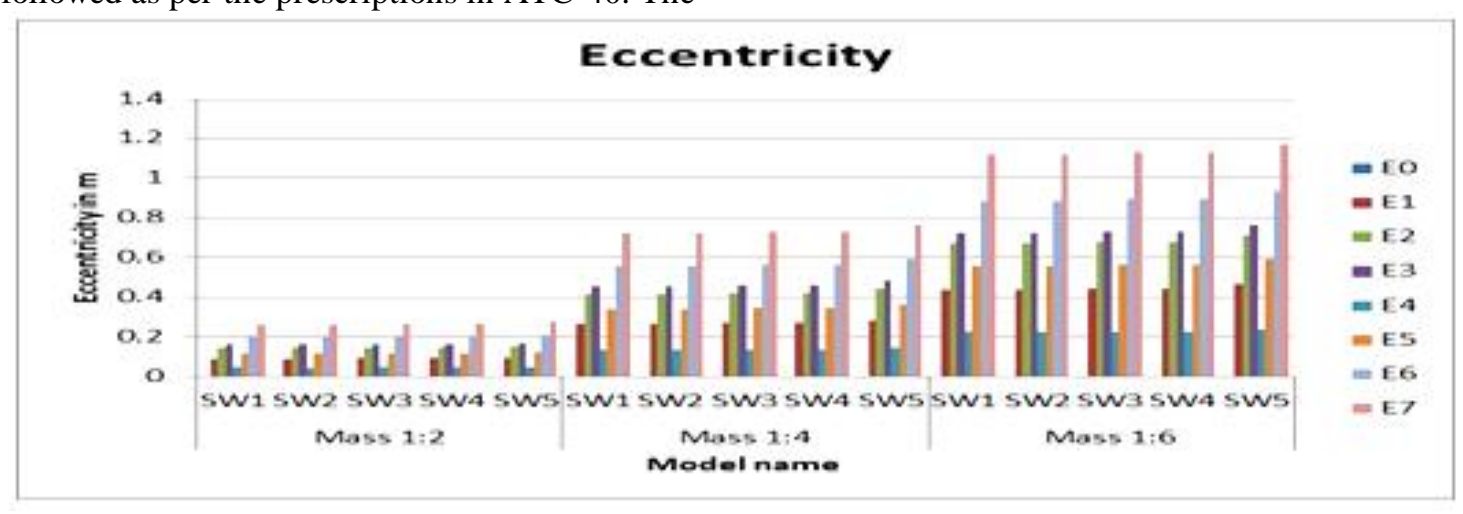

Fig. 4. Eccentricity

\section{B. Torsion}

Although in a building moments are unavoidable, torsional moment is that which all structural engineers try to eliminate as they cause undesirable responses in the structure. Provision of shear wall reduces the torsion in the building and the average torsion is observed in earthquake load combination and is shown in figure 5 .

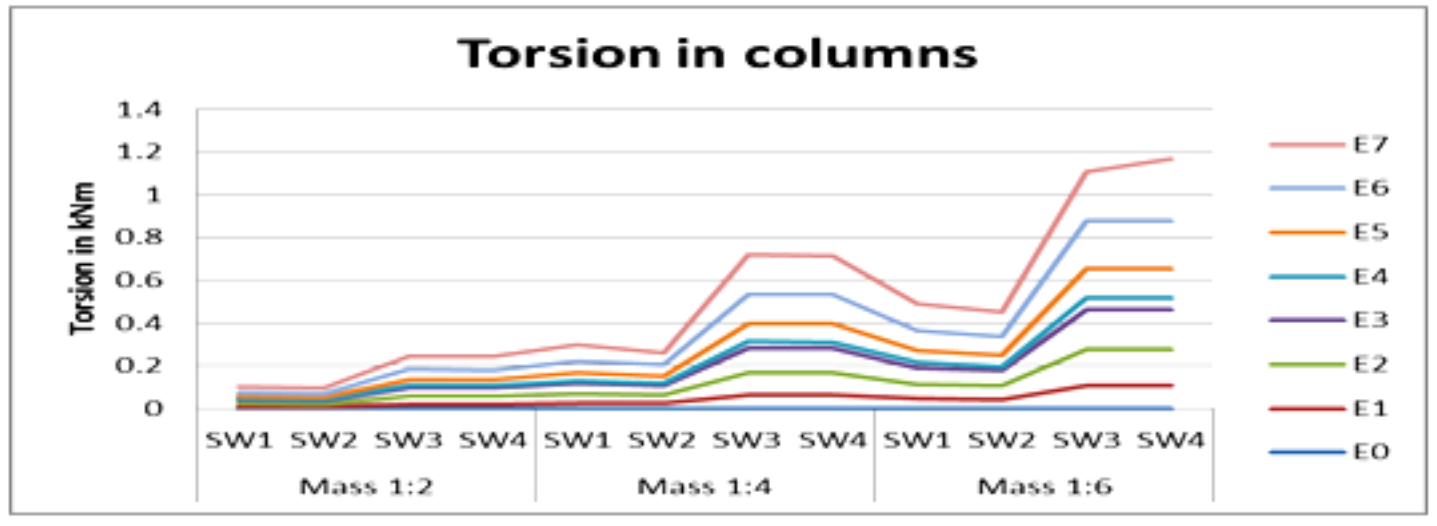

Fig. 5. Average Torsion in the columns

Torsion is zero for wind loading. For earthquake loading, rate of increase of torsion is directly proportional to that of eccentricity. For model SW5, that is, when a box type shear wall is provided at the core, the torsion has reduced by a drastic amount. When shear wall is provided at the outer edges also, torsion is seen to reduce. The increase in torsion when shear wall is provided around the core (SW4 \& SW5) is more for higher magnitudes of mass asymmetry. When the extent of asymmetry is higher as in model E7, the difference in the torsion for different positions of shear wall at the core is more.

\section{Top Storey Displacement}

The magnitude of displacement due to wind load is higher than that of seismic loads and increases with the eccentricity due to mass asymmetry. As the eccentricity increases the 
variation in displacement for positive and negative direction loading increases.

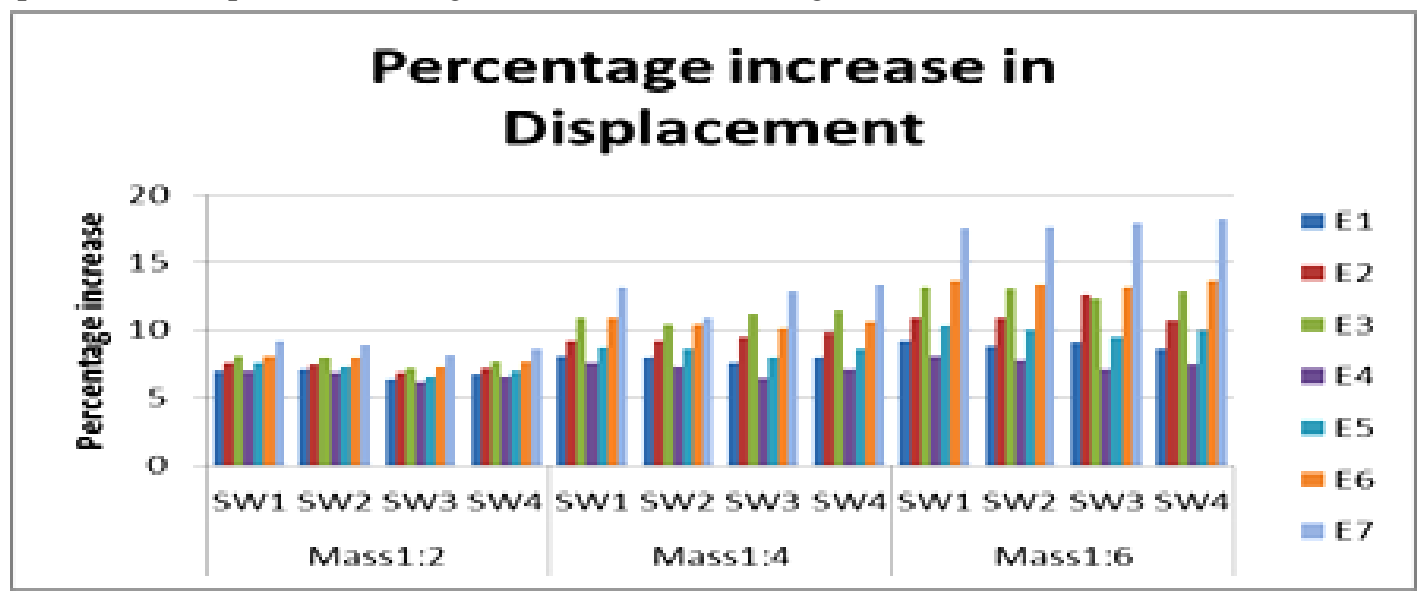

Fig. 6. Percentage increase in Top storey displacements due to eccentricity in the models

Structures with shear wall has lesser top storey displacement than those without shear wall as the shear wall resists the lateral forces and provides more stiffness. There is no significant increase in displacement with increase in extent of heavier mass but with increase in magnitude of mass, top storey displacement increases. When the increase in mass is 2 times, the percentage increase in displacement is minimum for shear wall near the core. Also the presence of shear wall reduces the difference in positive and negative direction loading behaviour of mass asymmetric buildings. A box type shear wall at the core gives the best resistance to lateral displacement.

\section{Base Shear and Storey drift}

Base shear due to seismic forces are found to increase steadily with mass as shown in figure 7. Storey drift is defined as the relative displacement of adjacent stories and is given by the following formula.

$\Delta=\left(\delta_{i}-\delta_{i-1}\right) / h$

Where, $\Delta$ - Storey drift, $\delta \mathrm{i}$ - Displacement of the $\mathrm{i}^{\text {th }}$ storey, $\mathrm{h}$ Storey height.

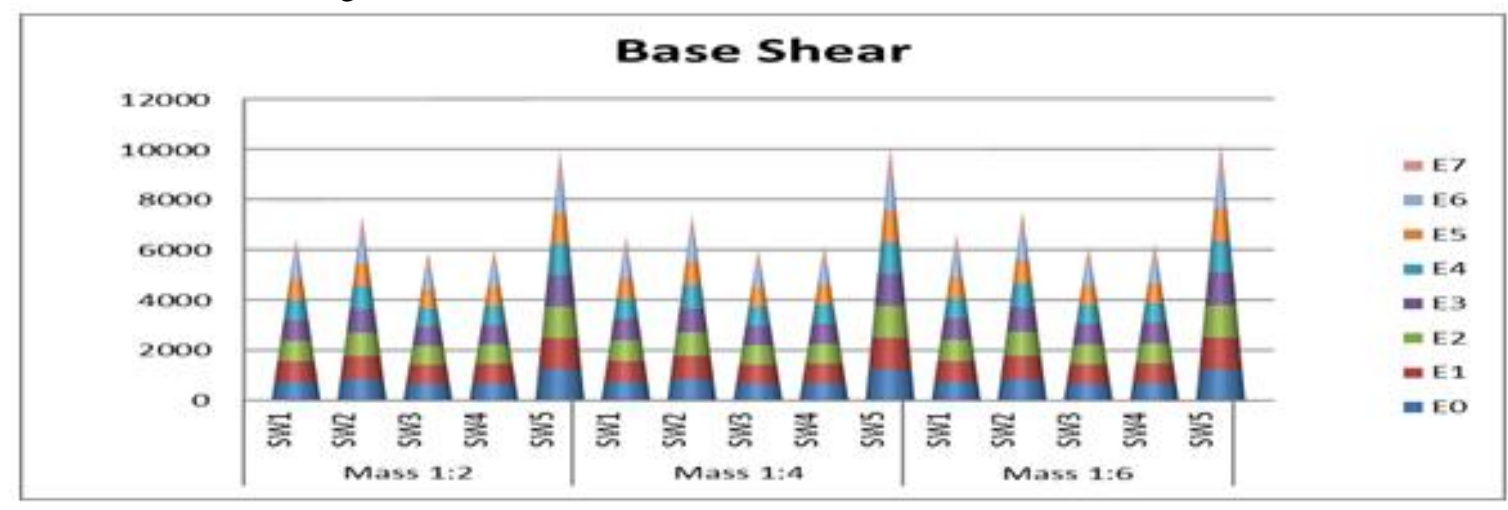

Fig. 7 Base shear due to seismic load in different models

The base shear increases with provision of shear wall. The buildings with shear wall near the core has lesser base shear because of the lesser length of wall. When a box type shear wall is provided at the core the base shear is seen to be maximum with about $150 \%$ increase in base shear. When shear wall is given at the corners the base shear is found to be lesser by $20 \%$ than when provided at the centre of outer edges. As the mass eccentricity increases so does the base shear. The increase in base shear is more with increase in magnitude of asymmetry rather than increase in the magnitude of mass. 


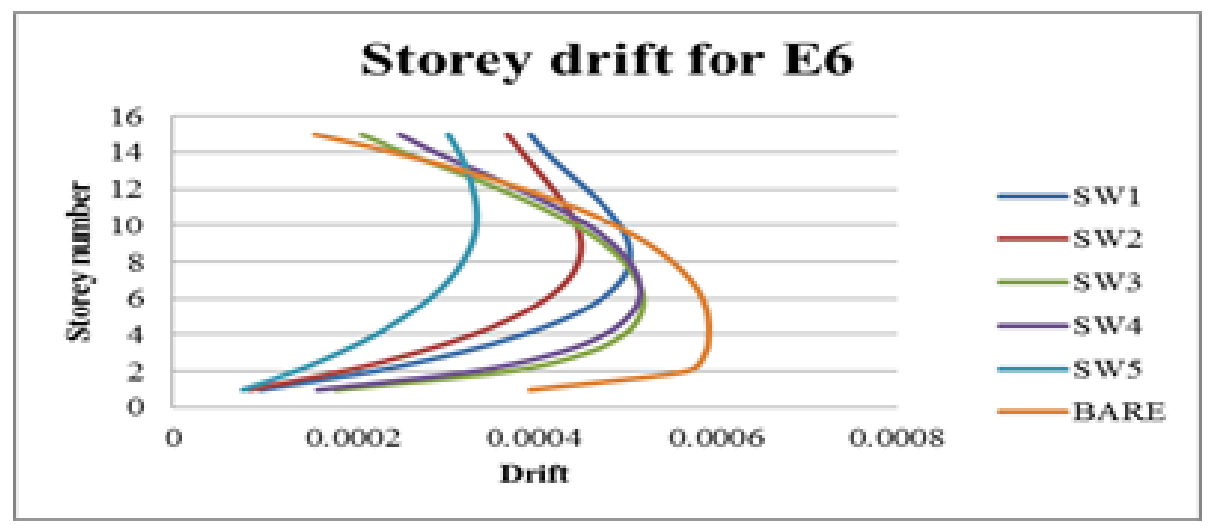

Fig. 8. Storey drift due to seismic load in Y direction for model E6 with mass ratio 1:6

The lateral behaviour of the structure changes with the position of shear wall as shown in figure 7 . When shear wall was provided the storey drift reduced by $14.7 \%$ for model SW1, 23.8\% for model SW2, $12.2 \%$ for model SW3, $12.8 \%$ for model SW4 and $43.4 \%$ for model SW5. For shear walls near the core, maximum drift is seen in the lower stories and for structures with shear wall in the outer edges, maximum drift is observed in the upper stories. Hence, either providing a box type shear wall at the core or simple shear walls on the outer edges reduces storey drift by a great amount.

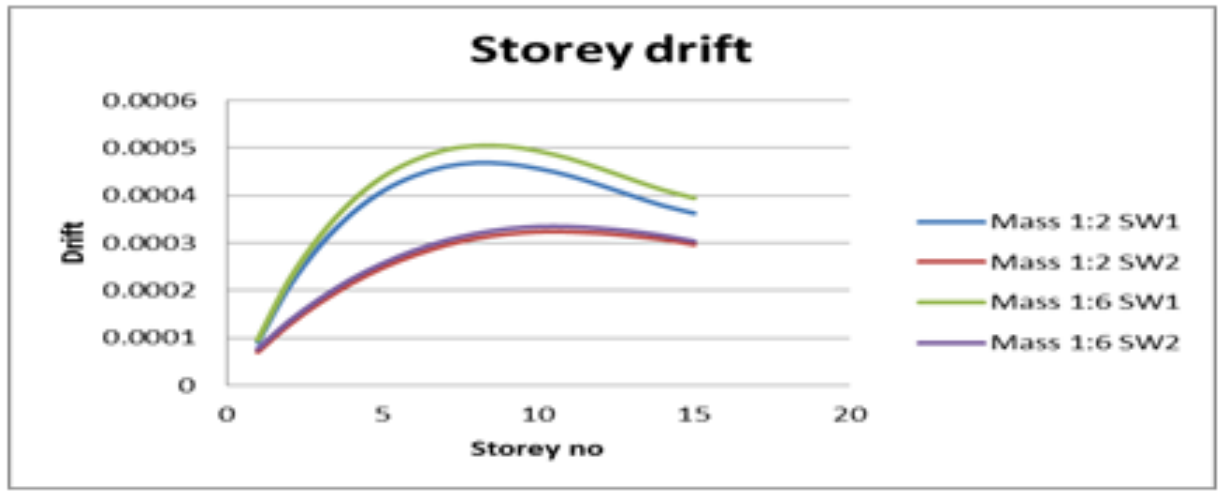

Fig. 9. Storey drift due to seismic load in Y direction for model E6

When shear wall is provided at the outer edges, the increase in drift with increase in eccentricity reduces more when compared to shear wall at the core.

\section{E. Non Linear Behaviour}

Pushover analysis is done for all the models. They are pushed above the target displacement and the sequence of formation of hinges are studied.

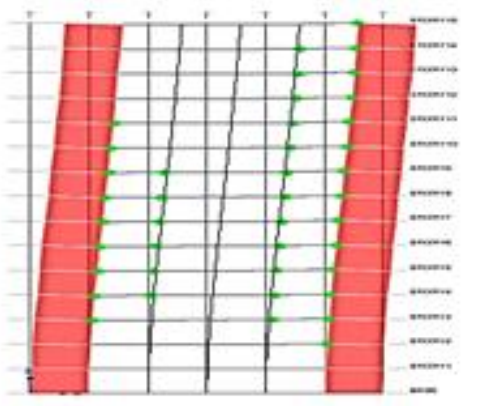

Fig 10. Formation of hinges in the model E5

For mass eccentric buildings with shear wall, hinges are formed mainly in the beams connected to the wall. Hinges are first formed in the middle stories. All hinges are within the Immediate Occupancy level (IO). Structures with asymmetry about one direction have almost same nonlinear behaviour as symmetrical structures. As the magnitude of mass increases, the hinges get concentrated on the asymmetric side.

\section{CONCLUSIONS}

The linear and nonlinear behaviour of all the models are studied and the following conclusions have been drawn.

1. Providing shear walls helps in reducing the torsion, displacement and storey drift thereby increasing lateral resistance.

2. With increase in mass magnitude or extent of heavier mass, the position of shear wall becomes more important. If the shear walls are provided symmetrically, eccentricity does not increase.

3. Base shear increases when shear wall is provided. The increase in base shear is more with increase in extent of 
heavier mass rather than increase in the magnitude of mass. It is maximum for box type shear wall at core.

4. Reduction in the time period of the structure is due to the presence of shear wall. The position of shear wall has only negligible effect on the time period of the structure. The time period is affected when the magnitude of mass increases.

5. Provision of shear wall at the core reduces the reinforcement in columns more than when provided at the outer edge. With increase in mass magnitude, only localised strengthening of columns in the form of reinforcement is required.

6. When shear wall is provided the plastic behaviour is mainly concentrated on the area near the wall which is due to the high moments in the beams connected to the wall.

A box type shear wall at the core is the best location for wall as it enhances the structural resistance to lateral loads. Due to the fact that an enclosed box area at the centre of the structure is not advisable from an architectural point of view; also openings would have to be provided in the wall to be used as a service lift core which reduces the effectiveness of shear wall, it is better to provide shear wall on the outer edges to improve lateral resistance of the structure.

\section{REFERENCES}

[1] Chittiprolu R and Ramancharla P K, "Significance of Shear Wall in High rise Irregular Buildings", International Journal of Education and Applied Research, Volume 4, Issue spl-2, Jan - June 2014, pp. 35-37

[2] Lee H and Ko D (2004), "Seismic response characteristics of high-rise RC wall buildings having different irregularities in lower stories", Journal of Structural Engineering, Volume 130, Number 2, pp. 271-284

[3] Rahangdale H and Satone S R, "Design and analysis of multi-storied building with effect of shear wall", International Journal of Engineering Research and Application, 2013, Volume 3, Issue 3, pp. 223-232.

[4] Agrawal A S (2012), "Effect Of Change In Shear Wall Location On Storey Drift Of Multistorey Building Subjected To Lateral Loads", International Journal of Engineering Research and Applications, Volume 2, Issue 3, pp.1786-1793S

[5] Ashraf M, Siddiqi Z A and Javed M A, "Configuration of a multi-story building subjected to lateral forces", Asian Journal of Civil Engineering, 2008, Volume 9, No. 5, pp. 525-537.

[6] Karnale AK B , "Comparative Seismic Analysis of High Rise And Low Rise RCC Building With Shear Wall", International Journal of Innovative Research in Science, Engineering and Technology, Volume 4, Issue 9, pp. 8450-8458

[7] Bureau of Indian Standard, IS 456:2000 Indian Standard Plain and Reinforced Concrete Code of Practice

[8] Bureau of Indian Standard, IS 1893 (Part 1):2002 Indian Standard Criteria for Earthquake Resistant Design Of Structures

[9] Bureau of Indian Standard, IS 875 (Part 3):1987 Indian Standard Code of practice for design loads for buildings and structures Part 3 Wind Loads (Second Revision)

[10] Applied Technology Council, ATC-40, Seismic Evaluation and Retrofit of Concrete Buildings, Volume 1, California, 1996.

[11] FEMA 356, Pre-standard and Commentary for the Seismic Rehabilitation of Buildings, November, 2000. 